\title{
Recalibrated Double Many-Body Expansion Potential Energy Surface and Dynamics Calculations for $\mathrm{HN}_{2}$
}

\author{
P. J. S. B. Caridade, L. A. Poveda, S. P. J. Rodrigues, and A. J. C. Varandas* \\ Departamento de Química, Universidade de Coimbra, 3004-535 Coimbra, Portugal
}

Received: October 20, 2006; In Final Form: December 19, 2006

\begin{abstract}
A single-sheeted double many-body expansion potential energy surface is reported for the lowest doublet state of $\mathrm{HN}_{2}$ by fitting additional multireference configuration interaction energies in the $\mathrm{N} \cdots \mathrm{NH}$ channel. A stratified analysis of the root-mean-squared error indicates an accuracy superior to that achieved for the previously reported form. Detailed dynamical tests are also performed for the $\mathrm{N}+\mathrm{NH}$ reaction using both the quasi-classical trajectory method and the capture theory, and the results are compared with available empirical data. The vibrational resonances of the $\mathrm{HN}_{2}$ metastable radical are also calculated and compared with previous theoretical predictions.
\end{abstract}

\section{Introduction}

Interest in $\mathrm{N}_{x} \mathrm{H}_{y}$ systems has been increasing in recent years because of their key role in the nitrogen chemistry, both in the gas phase and in the gas-solid interface. ${ }^{1}$ Specifically, $\mathrm{HN}_{2}$ is a well-known intermediary in the NO pollutant combustion reduction ${ }^{2-6}$ and in the noncatalytic radical mechanism that leads to ammonia formation. ${ }^{7}$ In a recent publication, Dickinson et al. ${ }^{8}$ stressed the importance of transport coefficients in $\mathrm{H}-\mathrm{N}_{2}$ binary mixtures to model hydrogen-air flames.

Although the $\mathrm{HN}_{2}$ radical is recognized as a metastable species, it has apparently never been explicitly detected by spectroscopic methods. In fact, only Selgren et al. ${ }^{9}$ reported results based on $\mathrm{HN}_{2}{ }^{+}$neutralization beam studies in which they observed radiative transitions (wavelength range 2700-4500 $\AA$ ) between $n=3$ Rydberg state of ${ }^{2} \mathrm{~A}^{\prime}$ and ${ }^{2} \mathrm{~A}^{\prime \prime}(\pi)$ using potassium targets. As claimed by the authors, ${ }^{9}$ this may constitute the first spectroscopic detection of the radical, although no other studies confirmed their analysis. An intriguing aspect of the $\mathrm{HN}_{2}$ radical is the long-standing discussion concerning its lifetime. Several theoretical results ${ }^{10-16}$ have predicted hydrodinitrogen to be short-lived $\left(10^{-8}-10^{-9} \mathrm{~s}\right)$, while kinetic models of the thermal selective noncatalytic reduction of NO by ammonia require it to have a long lifetime in order to rationalize the experimental results. ${ }^{2,17,18}$ Quoting Gu et al., ${ }^{14}$ "harmony between kinetic modeling studies and experiment can be achieved by postulating a lifetime of $10^{-4} \mathrm{~s}$ for the $\mathrm{HN}_{2}$ species", which is 4 orders of magnitude or so larger than the theoretical predictions. However, an ad hoc manipulation of the $\mathrm{HN}_{2}$ lifetime may not be the proper solution as other groups ${ }^{19}$ have alerted for missing reactions and chemical equilibria in the considered kinetic models, e.g., the fast dissociation/ recombination process $\mathrm{HN}_{2} \rightleftharpoons \mathrm{H}+\mathrm{N}_{2} \cdot{ }^{3,5,20,21}$ Moreover, Selgren et al. ${ }^{9}$ concluded that the $\mathrm{HN}_{2}$ lifetime should be less than 0.5 $\mu \mathrm{s}$.

\footnotetext{
* To whom correspondence should be addressed. E-mail varandas@qtvs1.qui.uc.pt.
}

To study this and other aspects related to the $\mathrm{HN}_{2}$ radical, we have recently reported ${ }^{15}$ a global single-sheeted DMBE (double many-body expansion) potential energy surface for the ground electronic doublet state of the title system $\left({ }^{2} \mathrm{~A}^{\prime}\right)$, hereafter denoted as DMBE I. This function has been calibrated from accurate multireference configuration interaction ${ }^{22}$ (MRCI) energies using the aug-cc-pVQZ (AVQZ) basis set of Dunning, ${ }^{23,24}$ which have been subsequently corrected semiempirically by using the DMBE-scaled external correlation (DMBESEC) method $^{25}$ to extrapolate to the complete basis set/complete configuration interaction limit. As for applications, the DMBE I potential energy surface has been employed ${ }^{16}$ both in classical and in quantum studies of various unimolecular and bimolecular reactions, as well as to calculate $\mathrm{H}-\mathrm{N}_{2}$ transport and diffusion coefficients. ${ }^{8}$ Although the accuracy of DMBE I is estimated to be $1.0 \mathrm{kcal} \mathrm{mol}^{-1}$, a spurious barrier of $0.5 \mathrm{~K}$ has been detected after publication in its long-range component, a finding also reported by Dickinson et al. ${ }^{8}$ Although this feature is unlikely to have any practical implications in reaction dynamics at temperatures of relevance in most physical and chemical processes, this may not be the case for low- and ultralowtemperature regimes. This prompted us to carry out further high level ab initio calculations for the $\mathrm{N}+\mathrm{NH}$ channel with a view to improve the reliability of the fitted potential energy surface. Such a work will be described in section 2 .

Experimentally, the rate constant of the $\mathrm{N}+\mathrm{NH}$ exothermic reaction has been the subject of a single direct measurement by Hack et al. ${ }^{26}$ It has also been studied ${ }^{20,21,27-29}$ indirectly based on assumptions that may have introduced some arbitrariness on its temperature dependence and even on its value at room temperature. In a previous publication, we have presented a quasi-classical trajectory/statistical mechanics study of the $\mathrm{N}$ $+\mathrm{NH} \rightleftharpoons \mathrm{N}_{2}+\mathrm{H}$ reactive system using the DMBE I potential energy surface. Although a fortuitous coincidence has led to good agreement with the reported experimental data and even with the suggested $T^{0.5}$ temperature-dependence of the rate 
TABLE 1: Numerical Values of the Extended Hartree-Fock Energy [Eq 2] for DMBE II

\begin{tabular}{|c|c|c|c|c|c|}
\hline coefficients & $P^{(1)}$ & $P^{(2)}$ & $P^{(3)}, P^{(4)}$ & $P^{(5)}, P^{(6)}$ & $P^{(7)}$ \\
\hline$c_{1} / a_{0}^{0}$ & -2.90158828 & -1.09895154 & 0.43148722 & -0.01393543 & 0.61624970 \\
\hline$c_{2} / a_{0}^{-1}$ & 0.39854688 & -1.69106240 & -0.95862589 & -0.00024907 & -0.02188633 \\
\hline$c_{3} / a_{0}^{-1}$ & 2.94933842 & 3.36317027 & -0.58841950 & 0.00242847 & 0.20525174 \\
\hline$c_{4} / a_{0}^{-2}$ & -0.78513361 & 0.10992062 & 1.29460955 & -0.00434843 & 0.02877663 \\
\hline$c_{5} / a_{0}^{-2}$ & -1.80500677 & -2.33894400 & 0.96554945 & -0.00221630 & -0.01318154 \\
\hline$c_{6} / a_{0}^{-2}$ & 1.97749883 & 1.50276065 & 1.11369917 & 0.00532874 & 0.07051309 \\
\hline$c_{7} / a_{0}^{-2}$ & -0.27097707 & 0.63566828 & 0.14998792 & -0.00245328 & -0.07077306 \\
\hline$c_{8} / a_{0}^{-3}$ & 0.57672213 & -1.12637632 & -0.80000327 & & \\
\hline$c_{9} / a_{0}^{-3}$ & 0.55527103 & -1.49242602 & -1.07619112 & & \\
\hline$c_{10} / a_{0}^{-3}$ & -0.42551937 & -0.55456205 & 0.26787584 & & \\
\hline$c_{11} / a_{0}^{-3}$ & 2.38311147 & 2.25672572 & -0.82818877 & & \\
\hline$c_{12} / a_{0}^{-3}$ & -0.00353209 & 1.29534898 & -0.14270347 & & \\
\hline$c_{13} / a_{0}^{-3}$ & 0.20356871 & 1.74408593 & -0.26975878 & & \\
\hline$c_{14} / a_{0}^{-4}$ & -0.11362941 & -0.03375161 & 0.56955400 & & \\
\hline$c_{15} / a_{0}^{-4}$ & -1.07422542 & -0.68556436 & 0.21002786 & & \\
\hline$c_{16} / a_{0}^{-4}$ & -0.82883383 & -0.12020553 & 0.50601702 & & \\
\hline$c_{17} / a_{0}^{-4}$ & 0.24120702 & 0.98954397 & -0.04587553 & & \\
\hline $\begin{array}{l}c_{17 /} / a_{0} \\
c_{18} / a_{0}^{-4}\end{array}$ & 0.43799969 & 0.66171509 & 0.69059305 & & \\
\hline $\begin{array}{l}c_{18} / a_{0} \\
c_{19} / a_{0}^{-4}\end{array}$ & 0.48111176 & 1.15964005 & -0.09833499 & & \\
\hline$c_{20} / a_{0}^{-4}$ & -1.55264396 & 0.95992522 & 0.32456237 & & \\
\hline$c_{21} / a_{0}^{-4}$ & 0.27216868 & 0.35208058 & 0.22641765 & & \\
\hline$c_{22} / a_{0}^{-4}$ & 0.40173631 & -0.06031124 & 0.18601286 & & \\
\hline$c_{23} / a_{0}^{-5}$ & 0.03482064 & -0.17962009 & -0.17925566 & & \\
\hline$c_{24} / a_{0}^{-5}$ & -0.40095342 & -0.40538698 & 0.00220662 & & \\
\hline$c_{25} / a_{0}^{-5}$ & 0.15075947 & 0.45669342 & -0.20627251 & & \\
\hline$c_{26} / a_{0}^{-5}$ & -0.34618938 & 0.42740386 & -0.30410104 & & \\
\hline$c_{27} / a_{0}^{-5}$ & -0.18318810 & -0.22534593 & -0.08384832 & & \\
\hline$c_{28} / a_{0}^{-5}$ & 0.30507092 & 0.69189675 & -0.26672995 & & \\
\hline$c_{29} / a_{0}^{-5}$ & 0.18675391 & 0.57350723 & 0.30028707 & & \\
\hline $\begin{array}{l}c_{29} / a_{0} \\
c_{30} / a_{0}^{-5}\end{array}$ & -1.00100158 & 0.34435255 & -0.41344558 & & \\
\hline $\begin{array}{l}l_{30} / a_{0} \\
c_{31} / a_{0}^{-5}\end{array}$ & -0.65963394 & -0.58579651 & -0.30281359 & & \\
\hline$c_{32} / a^{-5}$ & 0.10598629 & -0.18417302 & 0.17856970 & & \\
\hline$c_{32} / a_{0}^{-5}$ & 0.62854741 & -0.61234370 & 0.01915613 & & \\
\hline$c_{33} / a_{0}^{-5}$ & 0.16916360 & -0.03171154 & 0.00567697 & & \\
\hline $\begin{array}{l}c_{34} / a_{0} \\
c_{35} / a_{0}^{-6}\end{array}$ & 0.01037597 & 0.01504439 & 0.04748843 & & \\
\hline $\begin{array}{l}c_{35} / a_{0} \\
c_{36} / a^{-6}\end{array}$ & -0.00111739 & -0.10727743 & -0.02430580 & & \\
\hline $\begin{array}{l}c_{36} / a_{0} \\
c_{37} / a^{-6}\end{array}$ & 0.01033702 & 0.12956587 & 0.12168874 & & \\
\hline$c_{38} / a^{-6}$ & -0.12249987 & 0.09328784 & 010491031 & & \\
\hline$c_{3} / a^{-6}$ & 0.37473174 & -0.02091609 & 0.12687845 & & \\
\hline 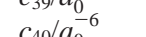 & -0.19645700 & 0.16339023 & $\begin{array}{l}0.1208 / 845 \\
0.12780671\end{array}$ & & \\
\hline$c_{41} / a_{0}^{-6}$ & -0.01456897 & -0.00861288 & $\begin{array}{r}0.12180071 \\
-0.03862858\end{array}$ & & \\
\hline$a_{0}-6$ & 0.17422860 & 0.01503896 & 0.11260976 & & \\
\hline$a_{2} / a_{0}^{-6}$ & 0.04993295 & 0.10767799 & -0.12218007 & & \\
\hline$c_{43} / a_{0}$ & -0.23819751 & 0.21241282 & 0.11121738 & & \\
\hline$c_{44} / a_{0}$ & 0.07810318 & -004887950 & 011388144 & & \\
\hline${ }^{C} 45 / a_{0}$ & -0.011316908 & 0.03710686 & -019009228 & & \\
\hline${ }^{C} 46 / a_{0}-6$ & 012781642 & -047284812 & -0.190092286 & & \\
\hline$c_{47 /} a_{0}-6$ & -008263450 & -001902151 & $\begin{array}{r}0.11990300 \\
-003046820\end{array}$ & & \\
\hline$c_{48} / a_{0}$ & 0.00203450 & -0.01902151 & -0.03046820 & & \\
\hline$c_{49} / a_{0}{ }_{-6}$ & 0.01158495 & $\begin{array}{r}0.06946968 \\
\end{array}$ & 0.18556616 & & \\
\hline$c_{50} / a_{0}$ & 0.12600504 & -0.15261714 & 0.23484907 & & \\
\hline$\gamma_{1}^{(j)} / a_{0}^{-1}$ & 1.58 & 0.10 & 1.60 & 0.29 & 0.69 \\
\hline$\gamma_{2}^{(j)} / a_{0}^{-1}$ & 1.16 & 1.33 & $-0.39,1.33$ & $1.27,1.02$ & 0.54 \\
\hline$\gamma_{3}^{(j)} / a_{0}^{-1}$ & 1.16 & 1.33 & $1.33,-0.39$ & $1.02,1.27$ & 0.54 \\
\hline$R_{1}^{(j), \text { ref }} / a_{0}$ & 1.85 & 2.55 & 1.90 & 7.461 & 4.80 \\
\hline$R_{2}^{(j), \text { ref }} / a_{0}$ & 2.75 & 2.15 & $2.20,4.10$ & $1.961,5.50$ & 2.40 \\
\hline$R_{3}^{(j), \text { ref } / a_{0}}$ & 2.75 & 2.15 & $4.10,2.20$ & $5.50,1.961$ & 2.40 \\
\hline
\end{tabular}

constant proposed by several authors, such a result has later been found to have been because of an improper sampling of the translational energy in ref 16 . The present recalibration of the DMBE potential energy surface (DMBE II) then gave us the possibility of correcting such an error when studying the bimolecular reactions in section 3. Finally, the spectroscopy of the metastable $\mathrm{HN}_{2}$ species on DMBE II is reported in section 4. For convenience, several energy units have been used: $1 E_{\mathrm{h}}=219474.63 \mathrm{~cm}^{-1}=627.509552 \mathrm{kcal} \mathrm{mol}^{-1}$, and $1 a_{0}$ $=0.529177211 \AA$.

\section{Potential Energy Surface}

According to the DMBE method, ${ }^{30}$ the single-valued potential energy surface assumes the form of a cluster expansion, where

$$
V^{(n)}=V_{\mathrm{EHF}}^{(n)}+V_{\mathrm{dc}}^{(n)}
$$

and $V_{\mathrm{EHF}}^{(n)}$ and $V_{\mathrm{dc}}^{(n)}$ are the $n$-body extended Hartree-Fock and dynamical correlation energies, respectively. Because of themodularity of DMBE, the recalibration procedure affects only 
TABLE 2: Stratified Root-Mean-Squared Deviations (in kcal $\mathrm{mol}^{-1}$ )

\begin{tabular}{rccc}
\hline & & \multicolumn{2}{c}{ rmsd } \\
\cline { 3 - 4 } energy & number of points & DMBE I $^{a}$ & DMBE II $^{b}$ \\
\hline 20 & 229 & 0.152 & 0.046 \\
40 & 335 & 0.337 & 0.366 \\
60 & 541 & 0.654 & 0.414 \\
80 & 570 & 0.753 & 0.509 \\
100 & 596 & 0.815 & 0.608 \\
120 & 667 & 0.905 & 0.641 \\
140 & 689 & 1.005 & 0.667 \\
160 & 824 & 1.049 & 0.644 \\
200 & 966 & 1.151 & 0.726 \\
500 & 1046 & 1.325 & 0.773 \\
1200 & 1071 & 4.087 & 0.785
\end{tabular}

${ }^{a}$ Reference $15 .{ }^{b}$ This work.

the three-body EHF energy term, and hence we need to consider only this term in the present work (the reader is addressed to ref 15 for other details). Note that, due to a misprint in eq 16 of ref 15 , there should be a negative sign in the three-body correlation energy term.

The three-body extended Hartree-Fock energy contribution assumes the distributed-polynomial ${ }^{31}$ form

$$
V_{\mathrm{EHF}}^{(3)}=\sum_{j=1}^{7} P^{(j)}\left(Q_{1}, Q_{2}, Q_{3}\right) \prod_{i=1}^{3}\left\{1-\tanh \left[\gamma_{i}^{(j)}\left(R_{i}-R_{i}^{j, \mathrm{ref}}\right)\right]\right\}
$$

where $P^{(j)}$ is the $j$ th polynomial written in terms of $Q$ coordinates, as defined in eq 22 of ref 15 . In this work, we have used two polynomials of sixth-order and one of secondorder centered in different $C_{2 v}$ geometries and two others of sixth-order plus two of second-order centered at collinear geometries. The least-squares fit has been done as previously ${ }^{15}$ but employing now 1074 MRCI/aug-cc-pVQZ energies suitably scaled by the DMBE-SEC method. ${ }^{25}$ Extra care has been put on medium and long-range regions of the $\mathrm{N}-\mathrm{NH}$ channel, as it plays a critical role in the calculation of the rate constant. Table
1 gathers the numerical values of the coefficients in eq 2 for the $\mathrm{HN}_{2}\left({ }^{2} \mathrm{~A}^{\prime}\right)$ DMBE II potential energy surface.

The quality of the recalibrated function can be assessed from the stratified root-mean-squared deviations (rmsd's) reported in Table 2. Although chemical accuracy ( $\mathrm{rmsd} \leq 1.0 \mathrm{kcal} \mathrm{mol}^{-1}$ ) is attained up to $2400 \mathrm{kcal} \mathrm{mol}^{-1}$ above the absolute minimum, one should claim only qualitative agreement at high energies because of the many electronic states that may be involved at such regimes and which cannot be accounted for by the singlesheeted function in eq 1 . For regions of interest in the $\mathrm{HN}_{2}$ unimolecular process (up to $40 \mathrm{kcal} \mathrm{mol}^{-1}$ ), the rmsd is smaller than $0.4 \mathrm{kcal} \mathrm{mol}^{-1}$ while for those relevant to study the $\mathrm{N}+$ $\mathrm{NH}$ reaction (up to $146 \mathrm{kcal} \mathrm{mol}^{-1}$ ) it is still only $0.7 \mathrm{kcal} \mathrm{mol}^{-1}$. A significant improvement has then been achieved with respect to DMBE I, with the data being probably fitted within the accuracy of the ab initio energies themselves.

A stationary-point analysis has been performed on the DMBE II potential energy surface, with the results being compared with those obtained from other ab initio methods, ${ }^{12-15}$ as well as DMBE I, ${ }^{15}$ in Tables 3 and 4 . For the most important topographical characteristics, the DMBE $\mathrm{I}^{15}$ and DMBE II functions are seen to be hardly distinguishable, even through the reported normal-mode analysis (the maximum deviation in the calculated vibrational frequencies is $20 \mathrm{~cm}^{-1}$ ). Such an agreement shows that the distributed-polynomial technique allows a refinement of the previously reported function without severely modifying regions that were considered as properly described by DMBE I. As for the $\mathrm{HN}_{2}$ decomposition process, the classical barrier is located at $10.6 \mathrm{kcal} \mathrm{mol}^{-1}$ above the $\mathrm{HN}_{2}$ minimum. Although this is slightly lower than the early ab initio value of Walch et al. ${ }^{11}$ and the extrapolated result of Walch and Partridge, ${ }^{13}$ the agreement with the proposed estimate of Gu et al. ${ }^{14}\left(10.0 \pm 1.0 \mathrm{kcal} \mathrm{mol}^{-1}\right)$ is very good. The calculated exothermicity for this process is $4.6 \mathrm{kcal} \mathrm{mol}^{-1}$, in excellent agreement with MRCI calculations ${ }^{15}$ and with the Walch and Partridge ${ }^{13}$ extrapolated value of $4.3 \mathrm{kcal} \mathrm{mol}^{-1}$. Our result is also only $0.7 \mathrm{kcal} \mathrm{mol}^{-1}$ higher than the value reported by $\mathrm{Gu}$ et al. ${ }^{14}$ using $\operatorname{CCSD}(\mathrm{T})$. An interesting feature of the work of Gu et al. ${ }^{14}$ is the wrong exothermicity that B3LYP calculations predict. Using the same basis set as $\operatorname{CCSD}(\mathrm{T})$, the $\mathrm{HN}_{2}$ is

TABLE 3: Major Stationary Points of the DMBE II Potential Energy Surface, Compared with the Most Recent Available Data $^{12-14}$

\begin{tabular}{|c|c|c|c|c|c|c|c|}
\hline feature & property & $\mathrm{KSW}^{a}$ & $\mathrm{CASSCF} / \mathrm{ICCI}^{b}$ & $\operatorname{CCSD}(\mathrm{T})^{c}$ & $\mathrm{MRCI}^{d}$ & $\mathrm{DMBE} \mathrm{I}^{e}$ & $\mathrm{DMBE} \mathrm{II}^{f}$ \\
\hline global minimun & $\begin{array}{l}R_{1} / a_{0} \\
R_{2} / a_{0} \\
R_{3} / a_{0} \\
\Delta V^{g} / \mathrm{kcal} \mathrm{mol}^{-1} \\
\omega_{1}(\mathrm{~N}-\mathrm{H}) / \mathrm{cm}^{-1} \\
\omega_{2}(\mathrm{~N}-\mathrm{N}) / \mathrm{cm}^{-1} \\
\omega_{3} \text { (bend) } / \mathrm{cm}^{-1}\end{array}$ & $\begin{array}{l}2.250 \\
3.600 \\
1.966 \\
3.8 \\
2653 \\
1826 \\
1047\end{array}$ & $\begin{array}{l}2.25 \\
3.814 \\
2.097 \\
4.31^{h}\end{array}$ & $\begin{array}{l}2.223 \\
3.588 \\
1.985 \\
3.8\end{array}$ & $\begin{array}{l}2.227 \\
3.586 \\
1.981 \\
4.5 \\
2916 \\
1818 \\
1118\end{array}$ & $\begin{array}{l}2.226 \\
3.595 \\
1.983 \\
4.5 \\
2887 \\
1862 \\
1086\end{array}$ & $\begin{array}{l}2.226 \\
3.595 \\
1.983 \\
4.5 \\
2875 \\
1842 \\
1096\end{array}$ \\
\hline $\begin{array}{l}\text { saddle point for } \\
\mathrm{H}+\mathrm{N}_{2} \text { reaction }\end{array}$ & $\begin{array}{l}R_{1} / a_{0} \\
R_{2} / a_{0} \\
R_{3} / a_{0} \\
\Delta V^{i} / \mathrm{kcal}, \mathrm{mol}^{-1} \\
\omega_{1}(\mathrm{~N}-\mathrm{H}) / \mathrm{cm}^{-1} \\
\omega_{2}(\mathrm{~N}-\mathrm{N}) / \mathrm{cm}^{-1} \\
\omega_{3} \text { (bend) } / \mathrm{cm}^{-1}\end{array}$ & $\begin{array}{l}2.139 \\
4.190 \\
2.703 \\
11.4 \\
1667 \mathrm{i} \\
1990 \\
749\end{array}$ & $\begin{array}{l}2.17 \\
4.149 \\
2.754 \\
11.34\end{array}$ & $\begin{array}{l}2.121 \\
4.145 \\
2.688 \\
10.7\end{array}$ & $\begin{array}{l}2.124 \\
4.135 \\
2.685 \\
10.6 \\
1619 \mathrm{i} \\
2155 \\
762\end{array}$ & $\begin{array}{l}2.125 \\
4.136 \\
2.688 \\
10.6 \\
1640 \mathrm{i} \\
2102 \\
763\end{array}$ & $\begin{array}{l}2.125 \\
4.137 \\
2.688 \\
10.6 \\
1624 \mathrm{i} \\
2104 \\
778\end{array}$ \\
\hline $\begin{array}{l}\text { saddle point for } \\
\mathrm{H}-\mathrm{N}_{2} \text { isomerization }\end{array}$ & $\begin{array}{l}R_{1} / a_{0} \\
R_{2} / a_{0} \\
R_{3} / a_{0} \\
\Delta V^{i} / \mathrm{kcal}, \mathrm{mol}^{-1} \\
\omega_{1}(\mathrm{~N}-\mathrm{H}) / \mathrm{cm}^{-1} \\
\omega_{2}(\mathrm{~N}-\mathrm{N}) / \mathrm{cm}^{-1} \\
\omega_{3} \text { (bend) } / \mathrm{cm}^{-1}\end{array}$ & & & & $\begin{array}{l}2.324 \\
2.285 \\
2.285 \\
48.5 \\
2676 \\
1660 \\
2278 \mathrm{i}\end{array}$ & $\begin{array}{l}2.326 \\
2.281 \\
2.281 \\
48.4 \\
2753 \\
1668 \\
2295 \mathrm{i}\end{array}$ & $\begin{array}{l}2.326 \\
2.281 \\
2.281 \\
48.4 \\
2753 \\
1671 \\
2275 \mathrm{i}\end{array}$ \\
\hline
\end{tabular}

${ }^{a}$ Reference $12 .{ }^{b}$ Reference $13 .{ }^{c}$ Reference 14 , considering the aug-cc-p VQZ basis set. ${ }^{d}$ Reference 15 , fitting a polynomial to a dense grid around each stationary point. ${ }^{e}$ Reference $15 .{ }^{f}$ This work. ${ }^{g}$ Relative to the $\mathrm{H}+\mathrm{N}_{2}$ asymptote. ${ }^{h}$ Extrapolated to the basis set limit, see ref 13 . ${ }^{i}$ Relative to the global minimum. 


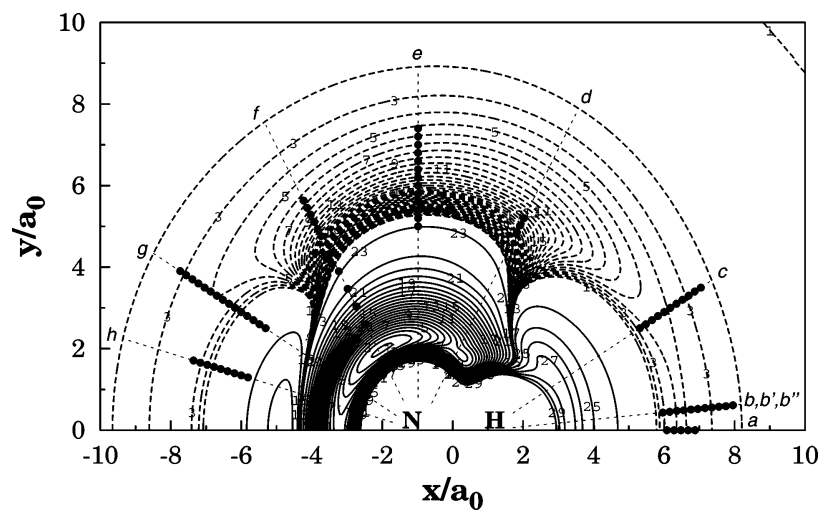

Figure 1. Isoenergy contour plot for the $\mathrm{N}$ around a partial relaxed $\mathrm{NH}$ molecule, $1.8 \leq R_{\mathrm{NH}} / a_{0} \leq 2.3$. Solid contours start at $-0.355 E_{\mathrm{h}}$ and equally spaced by $0.01 E_{\mathrm{h}}$, while the dashed ones start at -0.134 $E_{\mathrm{h}}\left[\mathrm{N}+\mathrm{NH}\left(R_{\mathrm{e}}\right)\right.$ energy] with increments of $0.0001 E_{\mathrm{h}}$. Shown in solid dots are the newly calculated MRCI ab initio geometries.

TABLE 4: Geometries and Energies of Other Important Stationary Points

\begin{tabular}{|c|c|c|c|c|}
\hline \multirow[b]{2}{*}{ property } & \multicolumn{3}{|c|}{ van der Waals } & \multirow{2}{*}{$\begin{array}{l}\text { linear TS } \\
\mathrm{N}-\mathrm{H}-\mathrm{N}\end{array}$} \\
\hline & $\min _{\mathrm{H} \cdots \mathrm{N}_{2}}$ & $\min _{\mathrm{N}-\mathrm{H} \cdots \mathrm{N}}$ & $\begin{array}{c}\mathrm{TS} \\
\mathrm{N} \cdots \mathrm{N}-\mathrm{H}\end{array}$ & \\
\hline$R_{1} / a_{0}$ & 2.075 & 7.467 & 6.846 & 4.758 \\
\hline$R_{2} / a_{0}$ & 7.112 & 1.961 & 1.965 & 2.379 \\
\hline$R_{3} / \mathrm{a}_{0}$ & 7.112 & 5.506 & 8.811 & 2.379 \\
\hline$E / E_{\mathrm{h}}$ & -0.3642 & -0.1305 & -0.1304 & -0.0937 \\
\hline$\Delta V / \mathrm{kcal} \mathrm{mol}^{-1}$ & $-0.1^{a}$ & $-0.2^{b}$ & $-0.1^{b}$ & $22.9^{b}$ \\
\hline$\omega_{1}(\mathrm{~N}-\mathrm{H}) / \mathrm{cm}^{-1}$ & 69 & 3198 & 4451 & $2828 \mathrm{i}$ \\
\hline$\omega_{2}(\mathrm{~N}-\mathrm{N}) / \mathrm{cm}^{-1}$ & 2337 & 45 & 119 & 567 \\
\hline$\omega_{3}($ bend $) / \mathrm{cm}^{-1}$ & 18 & 16 & $56 \mathrm{i}$ & 907 \\
\hline
\end{tabular}

${ }^{a}$ Relative to the $\mathrm{H}+\mathrm{N}_{2}$ asymptote. ${ }^{b}$ Relative to the $\mathrm{N}+\mathrm{NH}$ asymptote.

predicted to be stable by $3.3 \mathrm{kcal} \mathrm{mol}^{-1}$ in relation to the $\mathrm{H}+$ $\mathrm{N}_{2}$ asymptote, although the barrier height toward dissociation is close to the predicted value from the present work. As shown in Table 4, the recalibrated DMBE surface predicts also a new $\mathrm{NH} \cdots \mathrm{N}$ van der Waals minimum lying $0.2 \mathrm{kcal} \mathrm{mol}^{-1}$ below the $\mathrm{N}+\mathrm{NH}$ asymptote. For completeness, we also reported the $\mathrm{H} \cdots \mathrm{N}_{2}$ van der Waals minimum and the linear transition state structures in Table 4.

Because of similarities between the two DMBE potential energy surfaces, except for the $\mathrm{N}-\mathrm{NH}$ interaction channel, we restrict the discussion to this region. Shown as a contour plot in Figure 1 is a cut of the DMBE II potential energy surface for the $\mathrm{N}-\mathrm{NH}$ interaction, with the diatomic molecule being partially relaxed. The salient feature is the smaller attractive nature of the entrance region that leads to the $\mathrm{HN}_{2}$ minimum (cf. Figure 6 of ref 15). Also visible are a collinear $\mathrm{NH} \cdots \mathrm{N}$ van der Waals minimum and two collinear stationary points: one is the saddle point for $\mathrm{NH}-\mathrm{N}$ bending leading to isomerization and the other refers to the $\mathrm{N} \cdots \mathrm{HN}$ van der Waals minimum, which lies bellow the $\mathrm{N}+\mathrm{NH}$ asymptote by 0.1 $\mathrm{kcal} \mathrm{mol}^{-1}$ (see also Table 4). A more quantitative assessment of the fit is shown in the two panels of Figure 2, which display one-dimensional cuts (curves $\mathrm{a}-\mathrm{h}$ ) (these are indicated by the dashed lines in Figure 1) for different NH distances and Jacobi angles together with the newly calculated ab initio data. As Figure 2 shows, the new DMBE form describes within a few $\mathrm{cm}^{-1}$ the DMBE-SEC corrected MRCI energies. Also relevant is the absence of the spurious collinear barrier that appeared in DMBE I. ${ }^{15}$
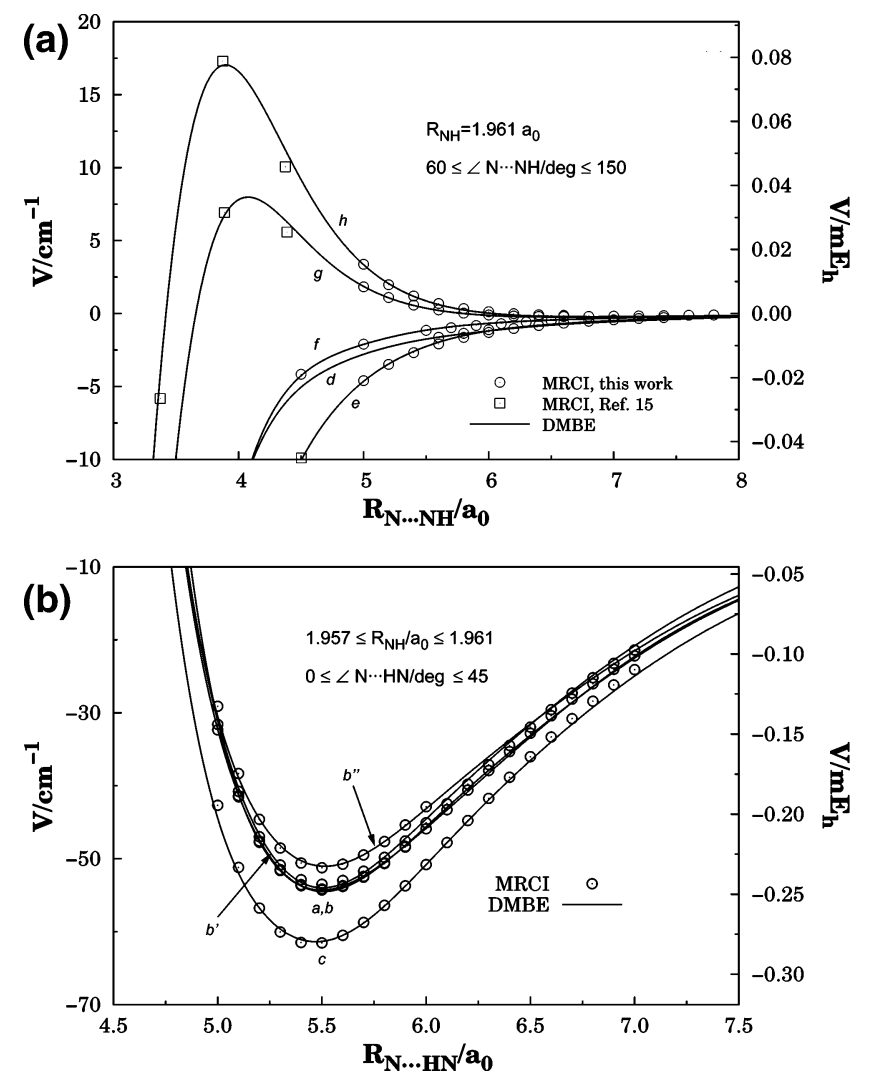

Figure 2. One-dimensional cuts for the long range interaction showing ab initio points calculated in the present work (open dots) and previously calculated (open squares): (a) $\mathrm{NH} \cdots \mathrm{N}$ and (b) $\mathrm{N} \cdots \mathrm{NH}$. The key letters refer to the dotted lines shown in Figure 1.

\section{The Reaction $\mathbf{N}+\mathbf{N H} \rightarrow \mathbf{N}_{2}+\mathbf{H}$ and Its Reverse}

The $\mathrm{N}+\mathrm{NH} \rightarrow \mathrm{N}_{2}+\mathrm{H}$ reaction and its reverse are important steps in the combustion of ammonia ${ }^{32,33}$ and hydrazine. ${ }^{21,34}$ Although the reaction is a simple triatomic reaction, only one direct experimental measurement of the rate constant has been reported ${ }^{26}$ by using a quasi-static flash photolysis cell (for room temperature). Indirectly, Whyte and Phillips ${ }^{28}$ have studied the $\mathrm{NH}$ decomposition produced by $\mathrm{N}+\mathrm{NH}_{2}$ by laser-induced fluorescence, having concluded that the total removal rate constant through reaction with atomic nitrogen is $(7.28 \pm 0.42)$ $\times 10^{13} \mathrm{~cm}^{3} \mathrm{~mol}^{-1} \mathrm{~s}^{-1}$. This value has been subsequently used by Zhan et al. ${ }^{29}$ to study the production of $\mathrm{NF}(\mathrm{b})$ and $\mathrm{IF}(\mathrm{B})$ in the $\mathrm{NH}_{3}-\mathrm{F}-\mathrm{F}_{2}-\mathrm{CF}_{3} \mathrm{I}$ reaction system. Since Whyte and Phillips $^{28}$ report the total removal rate constant, Zhan et al. ${ }^{29}$ have used half of this value, giving the same probability to the $\mathrm{NH}(X)$ and $\mathrm{NH}(A)$ channels. Other crude indirect estimates were reported in the literature ${ }^{21,27,35}$ based on simple formalisms. Unfortunately, our previous dynamics calculations ${ }^{16}$ were themselves affected by an error in the collision energy sampling, favoring high-energy values. Since DMBE II should be more accurate than DMBE I, only dynamics calculations on the former will be reported.

Following previous work, ${ }^{16}$ we have used the QCT method ${ }^{36}$ assuming a thermalized ro-vibrational distribution for the $\mathrm{NH}$ reactant molecule (see ref 37 for details), with the internal energies $\left(E_{v j}\right)$ being determined by solving numerically ${ }^{38}$ the time-independent Schrödinger equation and the realistic $\mathrm{NH}$ diatomic curve ${ }^{39}$ used in modeling both DMBE I and DMBE II. Translational energy sampling employed a MaxwellBoltzmann distribution for temperatures over the range 100$10000 \mathrm{~K}$, with 5000 trajectories being integrated for each batch 
TABLE 5: Summary of the QCT Results for the N + NH Reaction

\begin{tabular}{|c|c|c|c|c|c|c|c|}
\hline \multirow[b]{2}{*}{$T / \mathrm{K}$} & \multirow[b]{2}{*}{$b_{\max } / \AA$} & \multicolumn{2}{|r|}{$\mathrm{N}_{2}+\mathrm{H}$} & \multicolumn{2}{|r|}{$\mathrm{N}+\mathrm{N}+\mathrm{H}$} & \multicolumn{2}{|r|}{$\mathrm{NH}+\mathrm{N}$} \\
\hline & & $N_{r}$ & $10^{13} k_{1} / \mathrm{cm}^{3} \mathrm{~mol}^{-1} \mathrm{~s}^{-1}$ & $N_{r}$ & $10^{13} k_{\mathrm{d}} / \mathrm{cm}^{3} \mathrm{~mol}^{-1} \mathrm{~s}^{-1}$ & $N_{r}$ & $10^{13} \mathrm{k}_{\mathrm{i}} / \mathrm{cm}^{3} \mathrm{~mol}^{-1} \mathrm{~s}^{-1}$ \\
\hline 100 & 8.0 & 1816 & $3.96 \pm 0.07$ & & & & \\
\hline 300 & 6.9 & 1567 & $4.4 \pm 0.1$ & & & & \\
\hline 500 & 6.3 & 1527 & $4.6 \pm 0.1$ & & & & \\
\hline 1000 & 5.7 & 1434 & $5.0 \pm 0.1$ & & & & \\
\hline 2000 & 5.2 & 1304 & $5.4 \pm 0.1$ & & & & \\
\hline 3000 & 4.9 & 1276 & $5.7 \pm 0.1$ & & & 10 & $0.04 \pm 0.01$ \\
\hline 4000 & 4.7 & 1280 & $6.1 \pm 0.2$ & & & 26 & $0.12 \pm 0.02$ \\
\hline 5000 & 4.6 & 1271 & $6.5 \pm 0.2$ & 8 & $0.04 \pm 0.01$ & 56 & $0.29 \pm 0.04$ \\
\hline 6000 & 4.6 & 1214 & $6.8 \pm 0.2$ & 24 & $0.13 \pm 0.03$ & 75 & $0.42 \pm 0.05$ \\
\hline 7000 & 4.6 & 1183 & $7.1 \pm 0.2$ & 73 & $0.44 \pm 0.05$ & 99 & $0.60 \pm 0.06$ \\
\hline 10000 & 4.6 & 1024 & $7.4 \pm 0.2$ & 209 & $1.5 \pm 0.1$ & 166 & $1.20 \pm 0.09$ \\
\hline
\end{tabular}

using the VENUS $96^{40}$ code. Table 5 gathers the calculated rate constants for $\mathrm{H}+\mathrm{N}_{2}$ formation using DMBE II as obtained from

$$
k(T)=g_{\mathrm{e}}\left(\frac{8 k_{\mathrm{B}} T}{\pi \mu_{\mathrm{N}+\mathrm{NH}}}\right)^{1 / 2} \pi b_{\max }^{2} \frac{N_{r}}{N}
$$

where $g_{\mathrm{e}}=1 / 6$ and is the electronic degeneracy factor, $\mu$ the reduced mass of the colliding species, and $k_{\mathrm{B}}$ the Boltzmann constant. Assuming $68 \%$ confidence, the associated error is $\Delta k(T)=k(T)\left[\left(N-N_{r}\right) /\left(N N_{r}\right)\right]^{1 / 2}$.

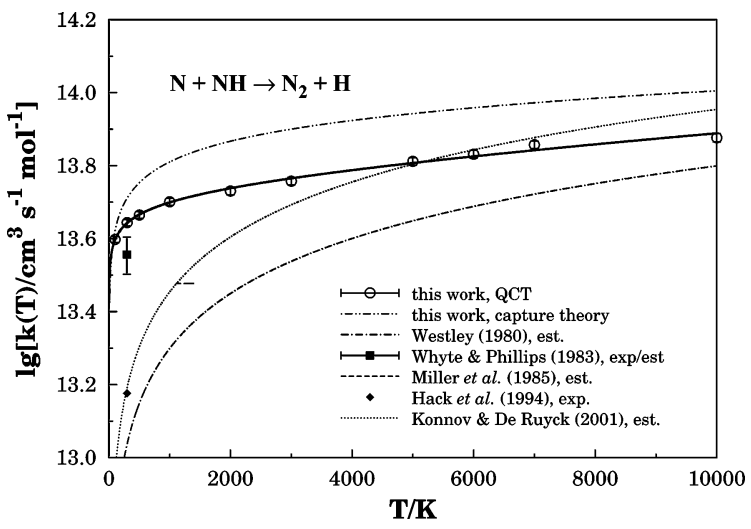

Figure 3. Rate coeffcient for the $\mathrm{N}_{2}+\mathrm{H}$ formation as a function of temperature. The open symbols denote the QCT calculations using DMBE II, while the solid line indicates the Arrhenius fit. Also shown are the classical capture calculations. For comparison we plot estimates from various sources ${ }^{21,27,29,35}$ and the experimental value of Hack et al. ${ }^{26}$

Figure 3 shows the calculated rate constant for $\mathrm{N}_{2}$ formation as a function of temperature. For convenience, the results were fitted to a three-parameter Arrhenius form,

$$
k(T)=A T^{m} \exp (-B / T)
$$

leading to the optimum least-squares parameters $A=4.88 \times$ $10^{13} \mathrm{~K}^{-m} \mathrm{~cm}^{3} \mathrm{~mol}^{-1} \mathrm{~s}^{-1}, m=-0.094$, and $B=-0.025 \mathrm{~K}$. The shape of the calculated curve shows a typical capture-type regime for low temperatures, which can be rationalized by the barrierless behavior of the $\mathrm{N}+\mathrm{NH}$ interaction. Because of this, we may apply capture theory (ref 41 and references therein) to highlight the low-temperature trend of the QCT results.

Consider the spherically averaged long-range interaction for each ro-vibrational combination of $\mathrm{N}+\mathrm{NH}(v, j)$ to be described by

$$
V_{l r}^{v j}(r)=-\left\langle C_{n}^{v j}\right\rangle r^{-n_{v j}}
$$

where $\left\langle C_{n}^{v j}\right\rangle$ is the effective long-range coefficient of power $n_{v j}$ and $r$ is the atom-diatom separation. The parameters in eq 5 can then be approximated by a least-squares fit to the longrange spherically averaged potential assuming the $\mathrm{NH}$ distance is fixed at the quantum mechanical expectation value of the $(v, j)$ state. The state-specific rate constant assumes the form ${ }^{42}$

$$
\begin{aligned}
k_{\text {cap }}^{v j}(T)=g_{\mathrm{e}}(T) \frac{2^{\left(3 n_{v j}-4\right) / 2 n_{v j}} n_{v j} \pi^{1 / 2}}{\left(n_{v j}-2\right)^{\left(n_{v j}-2\right) / n_{v j}} \mu^{1 / 2}} \Gamma\left(\frac{2 n_{v j}-2}{n_{v j}}\right) \times \\
\left(k_{\mathrm{B}} T\right)^{\left(n_{v j}-4\right) / 2 n_{v j}\left\langle C_{n}^{v j}\right\rangle^{2 / n_{v j}}}
\end{aligned}
$$

with $\Gamma$ being the gamma function. The total rate coefficient can then be obtained by the usual averaging procedure leading to

$$
k_{\text {cap }}(T)=Q_{\mathrm{vr}}^{-1}(T) \sum_{v j}^{\mathrm{NH}}(2 j+1) k_{\text {cap }}^{v j}(T) \exp \left(-\frac{E_{v j}}{k_{\mathrm{B}} T}\right)
$$

where $Q_{\mathrm{vr}}$ is the reactants $\mathrm{NH}$ ro-vibrational partition function. Figure 3 compares the rate constant predicted by capture theory with our QCT results. Clearly, the reaction obeys a capturetype regime at low temperatures. Because of the high exothermicity, the recrossing value is expected to be small, especially for temperatures up to $300 \mathrm{~K}$ or so, and hence will be ignored. Note that for temperatures higher than $3000 \mathrm{~K}$, the capture theory results are only given for qualitative analysis, as the method should no longer be reliable. Note further that for high translational and internal energies resulting from the sampling procedure, the diatomic molecule cannot reorient to find the most favorable attacking geometry, and hence the rate constant becomes nearly temperature-independent. This behavior has been predicted by Miller et al., ${ }^{18}$ with $k(1100 \leq T / \mathrm{K} \leq 1400)$ $=3 \times 10^{13} \mathrm{~cm}^{3} \mathrm{~s}^{-1} \mathrm{~mol}^{-1}$, our value being about 2.6 times larger. Note that other channels may open at high temperatures, namely, isomerization and total fragmentation; for completeness, these rate constants are also reported in Table 5. Note further that the $T^{0.5}$-dependence proposed by Westley ${ }^{27}$ and used recently by Konnov and De Ruyck ${ }^{20,21}$ is not verified by the present results.

Also shown in Figure 3 is the experimental data of Hack et al., ${ }^{26} k=1.5 \times 10^{13} \mathrm{~cm}^{3} \mathrm{~s}^{-1} \mathrm{~mol}^{-1}$, which has been obtained for room temperature. Their result is nearly 3 times lower than our QCT value and the capture-theory result. Even including a crude $20 \%$ estimate of possible error, ${ }^{26}$ the difference remains substantial. In turn, the agreement with the experimental estimate of Whyte and Phillips ${ }^{28}$ is satisfactory. Note, however, that the partition of the total rate of NH removal may not be equal for both electronic states as proposed by Zhan et al. ${ }^{29}$ Thus, the observed discrepancies between the calculated and measured rate constants for the title system may be attributed both to 
experimental difficulties and to the noninclusion of nonadiabatic effects in the theory as complicated electronic crossings ${ }^{43,44}$ are not taken into account by the single-sheeted DMBE II form. Of course, the use of classical mechanics cannot also be excluded as a source of error. However, we emphasize the high quality of the ab initio data and DMBE II fit and the fact that classical mechanical methods work extremely well for rate constant calculations even for the extreme case of three hydrogen atoms. ${ }^{45}$ In summary, we can hardly assign the source of discrepancy between the experimental and theoretical results without going beyond the adiabatic picture and/or performing more accurate measurements.

For the $\mathrm{H}+\mathrm{N}_{2}$ endothermic reaction, we have used microreversibility as in previous work. ${ }^{16}$ Thus, the $\mathrm{H}+\mathrm{N}_{2}$ formation rate constant assumes the form

$$
K(T)=\frac{k_{1}(T)}{k_{-1}(T)}
$$

where $k_{1}$ and $k_{-1}$ are the $\mathrm{N}_{2}$ and $\mathrm{NH}$ formation rate constants, respectively. Using the Arrhenius parameters reported ${ }^{16}$ for the equilibrium constant, $k_{-1}(T)$ can be expressed by the corresponding coefficients: $A=1.40 \times 10^{15} \mathrm{~K}^{-m} \mathrm{~cm}^{3} \mathrm{~mol}^{-1} \mathrm{~s}^{-1}, m$ $=-0.10$, and $B=-74450 \mathrm{~K}$. To our knowledge, the only estimate available for comparison is from the GRI-Mech 3.0, ${ }^{46}$ which is based on statistical thermodynamical data for the equilibrium constant and the reported $k_{1}(T=298 \mathrm{~K})$ value of Hack et al. ${ }^{26}$ The agreement is seen to be fairly good, although the temperature dependence, also based on eq 8 , has been obtained using a single value of the rate constant. We should note that although rate constants for $\mathrm{NH}+\mathrm{N}$ formation are reported for temperatures down to room temperature, their estimates may suffer from considerable error below $2000 \mathrm{~K}$. Quantitatively, we predict the $\mathrm{NH}+\mathrm{N}$ rate constant formation to be $4.35(4.43) \times 10^{-2}, 7.27(6.80) \times 10^{1}$, and $10.2(9.1) \times$ $10^{3} \mathrm{~cm}^{3} \mathrm{~s}^{-1} \mathrm{~mol}^{-1}$ for $T=2000,2500$, and $3000 \mathrm{~K}$, respectively, with the values in parentheses being from GRI-Mech. ${ }^{46}$

\section{The Reaction $\mathbf{N}+\mathbf{N H} \rightarrow \mathbf{N}_{2}+\mathbf{H}$ and Its Reverse}

The study of the radical lifetime and $\mathrm{HN}_{2} \rightarrow \mathrm{N}_{2}+\mathrm{H}$ dissociative process using the DMBE II potential energy surface has been carried out as in ref 16 using the complex method. ${ }^{47,48}$ Assuming an isolated resonance, the lifetime $\left(\tau_{n}\right)$ can be estimated by the associated width $\left(\Gamma_{n}\right)$ according to the expression $\tau_{n}=\hbar / \Gamma_{n}$, while the unimolecular decay of the state is given by $k_{n}=\Gamma_{n} / \hbar$. The key elements for the unimolecular decay rate constant and lifetime calculation are the resonance width and the separation between resonances. Our results were obtained using the DVR3D ${ }^{49}$ code and Jacobi coordinates: $r$, the $\mathrm{N}_{2}$ internuclear distance, $R$, the atom-diatom separation, and $\theta$, the orientation angle between the vectors $\mathbf{R}$ and $\mathbf{r}$. The primitive DVR basis employed $n_{r}=40, n_{R}=65$, and $n_{\theta}=80$, with the parameters of the Morse-like functions being $r_{\mathrm{e}}=2.3$ $a_{0}, D_{\mathrm{e}, r}=0.8 E_{\mathrm{h}}$, and $\omega_{\mathrm{e}, r}=0.02 E_{\mathrm{h}}$ for the coordinate $r$, and $R_{\mathrm{e}}=4.3 a_{0}, D_{\mathrm{e}, R}=0.8 E_{\mathrm{h}}$, and $\omega_{\mathrm{e}, R}=0.01 E_{\mathrm{h}}$ for $R$. The overall process utilized a truncation/diagonalization procedure, resulting in a 3000 dimensional secular problem. The lowest 1000 states have been retained for the complex calculations with the parameters of the negative imaginary potential being varied over the ranges $5.4 \leq R_{\min } / a_{0} \leq 5.8$ and $0.004 \leq \lambda / E_{\mathrm{h}} \leq 0.2$.

Table 6 gathers the energies and widths of the resonances calculated for the DMBE II potential energy surface, together with those previously reported ${ }^{16}$ for DMBE I. Also shown for comparison are the results of $\mathrm{Li}$ and $\mathrm{Guo}^{50}$ using double
TABLE 6: Resonance Parameters for the $\mathbf{H N}_{\mathbf{2}}$ Radical

\begin{tabular}{|c|c|c|c|c|c|c|}
\hline \multirow[b]{2}{*}{ state } & \multicolumn{2}{|c|}{$\mathrm{Li}$ and $\mathrm{Guo}^{a}$} & \multicolumn{2}{|c|}{$\mathrm{DMBE} \mathrm{I}^{b}$} & \multicolumn{2}{|c|}{$\mathrm{DMBE}_{\mathrm{II}}{ }^{c}$} \\
\hline & $E / \mathrm{cm}^{-1}$ & $\Gamma / \mathrm{cm}^{-1}$ & $E / \mathrm{cm}^{-1}$ & $\Gamma / \mathrm{cm}^{-1}$ & $E / \mathrm{cm}^{-1}$ & $\Gamma / \mathrm{cm}^{-1}$ \\
\hline$(000)$ & 4045.17 & 0.0019 & 4416.3 & 0.013 & 4409.1 & 0.010 \\
\hline (010) & 5115.80 & 0.034 & 5500.7 & 0.16 & 5491.0 & 0.13 \\
\hline (001) & 5766.90 & 2.09 & 6187.6 & 10.6 & 6172.9 & 9.1 \\
\hline (020) & 6220.55 & 1.50 & 6573.0 & 9.6 & 6555.4 & 7.7 \\
\hline (100) & 6386.4 & 55.8 & 6712 & 137 & 6702 & 134 \\
\hline (011) & 6789.8 & 8.18 & 7242 & 35 & 7224 & 29 \\
\hline (030) & 7289.4 & 13.5 & 7627 & 41 & 7609 & 34 \\
\hline (002) & 7483.0 & 56.7 & 7962 & 39 & 7938 & 37 \\
\hline (021) & 7879.6 & 34.6 & 8294 & 73 & 8273 & 73 \\
\hline (040) & 8312.9 & 42.3 & 8655 & 127 & 8643 & 69 \\
\hline (012) & 8559.2 & 79.6 & 9001 & 63 & 8981 & 60 \\
\hline (003) & 9174.4 & 94.6 & 9695 & 96 & 9680 & 64 \\
\hline
\end{tabular}

${ }^{a}$ Potential energy surface from ref $12 .{ }^{b}$ Potential energy surface from ref $15 .{ }^{c}$ This work.

Chebyshev autocorrelation functions based on the KSW potential energy surface. For levels up to $7627 \mathrm{~cm}^{-1}$, the differences with DMBE I are less than $15 \mathrm{~cm}^{-1}$, which shows the similarities between the two surfaces in the region of the $\mathrm{HN}_{2}$ minimum. We observe as before ${ }^{16}$ that our calculated energies are systematically higher than the values reported by $\mathrm{Li}$ and $\mathrm{Guo}^{50}$ and that level splittings due to tunneling are negligible. Such differences can be attributed to small topographical differences between the two surfaces because of the distinct ab initio methods and electronic basis sets employed. Comparing the lifetime for the six leading states of $\mathrm{HN}_{2}$ reported in Table 6 , we conclude that all theoretical predictions are in reasonably good agreement with each other. As anticipated by the structural similarities between the different potential energy surfaces, the $\mathrm{HN}_{2}$ lifetime is predicted to range from $10^{-9}$ to $10^{-13} \mathrm{~s}$, in contradiction with the postulated value of $10^{-4} \mathrm{~s}$ suggested by kinetic modelers.

For completeness, we have calculated the unimolecular rate constant $k(T)$ by assuming the high-pressure limit:

$$
k(T)=\frac{1}{Q_{\mathrm{HN}_{2}}} \sum_{k} k_{n} \exp \left(-\frac{\Delta E_{n}}{k_{\mathrm{B}} T}\right)
$$

where $Q_{\mathrm{HN}_{2}}$ is the $\mathrm{HN}_{2}$ partition function and $k_{n}=1 / \tau_{n}$. The results turn out to be almost indistinguishable from those reported elsewhere ${ }^{16}$ and hence will be omitted.

\section{Concluding Remarks}

A novel (DMBE II) single-sheeted DMBE potential energy surface has been reported for the lowest doublet state of $\mathrm{HN}_{2}$ by fitting accurate ab initio MRCI energies. As in previous work, such energies have first been corrected semiempirically to account for the basis set/configuration interaction finite sizes by using the DMBE-SEC method. The new fit shows a rootmean-squared deviation much smaller than DMBE I, which is possibly within the accuracy of the fitted ab initio points.

To test the DMBE II potential energy surface, a QCT study of the $\mathrm{N}+\mathrm{NH}$ exothermic reaction has also been performed. Although it is a simple atom-diatom elementary reaction studied on an accurate potential energy surface, a comparison with the experimental data reported in the literature shows at best fair agreement. Also, the postulated temperature-dependence of $T^{0.5}$ used in previous theoretical models for this reaction could not be confirmed. To investigate the origin of the predicted temperature-dependence at low temperatures, calculations have been performed using classical capture theory and shown to be 
in good agreement with the QCT ones. Finally, the resonance states for the metastable $\mathrm{HN}_{2}$ minima have been found to be in good agreement with those calculated using DMBE I. Further experimental and theoretical work is clearly necessary to clarify the pending issues.

Acknowledgment. This work has the financial support of the European Community (Contract HPRN-CT-2002-00170) and Fundacão para a Ciência e a Tecnologia, Portugal (Contracts POCI/QUI/60501/2004, POCI/AMB/60261/2004, and REEQ/ 128/QUI/2005).

\section{References and Notes}

(1) Hellman, A.; Baerends, E. J.; Biczysko, M.; Bligäard, T.; Christensen, C. H.; Clary, D. C.; Dahl, S.; v.-Harrevelt, R.; Honkala, K.; Jonsson, H.; Kroes, G. J.; Luppi, M.; Manthe, U.; Norskov, J. K.; Olsen, R. A.; Rossmeisl, J.; Skúlason, E.; Tautermann, C. S.; Varandas, A. J. C.; Vincent, J. K. J. Phys. Chem. B 2006, 110, 17719.

(2) Miller, J. A.; Bowman, C. G. Prog. Energy Combust. Sci. 1989, $15,287$.

(3) Bozzelli, J. W.; Dean, A. M. Int. J. Chem. Kinet. 1995, 27, 1097. 274.

(4) Hayhurst, A. N.; Hutchinson, E. M. Combust. Flame 1998, 114

(5) Hughes, K. J.; Tomlin, A. S.; Hampartsoumian, E.; Nimmo, W.; Zsély, I. G.; Ujvári, M.; Turányi, T.; Clague, A. R.; Pilling, M. J. Combust. Flame 2001, 124, 573.

(6) Tomeczek, J.; Gradoń, B. Combust. Flame 1998, 133, 311.

(7) Hwang, D.; Mebel, A. M. J. Phys. Chem. A 2003, 107, 2865.

(8) Dickinson, A. S.; Ern, A.; Vesovic, V. Mol. Phys. 2005, 103, 1895.

(9) Selgren, S. F.; McLaughlin, P. W.; Gellene, G. I. J. Chem. Phys. 1989, 90, 1624

(10) Walch, S. P.; Duchovic, R. J.; Rohlfing, C. M. J. Chem. Phys. 1989 90,3230 .

(11) Walch, S. P. J. Chem. Phys. 1990, 93, 2384.

(12) Koizumi, H.; Schatz, G. C.; Walch, S. P. J. Chem. Phys. 1991, 95 , 4130.

(13) Walch, S. P.; Partridge, H. Chem. Phys. Lett. 1995, 233, 331

(14) Gu, J.; Xie, Y.; Schaefer, H. F., III J. Chem. Phys. 1998, 108, 8029.

(15) Poveda, L. A.; Varandas, A. J. C. J. Phys. Chem. 2003, 107, 7923

(16) Caridade, P. J. S. B.; Rodrigues, S. P. J.; Sousa, F.; Varandas, A. J. C. J. Phys. Chem. A 2005, 109, 2356.

(17) Miller, J. A.; Branch, M. C.; Kee, R. J. Combust. Flame 1981, 81, 43.

(18) Miller, J. A.; Glarborg, P. Int. J. Chem. Kinet. 1999, 31, 757.

(19) Dean, A. M. Proceedings of the International Conference on the Foundations of Molecular Modeling and Simulation (FOMMS); AIChE Symposium Series, 2001; Vol. 97, p 84.

(20) Konnov, A. A.; De Ruyck, J. Combust. Sci. Technol. 2001, 168, 1.

(21) Konnov, A. A.; De Ruyck, J. Combust. Flame 2001, 124, 106.

(22) Werner, H.-J.; Knowles, P. J. J. Chem. Phys. 1988, 89, 5803.

(23) Dunning, T. H. J. Chem. Phys. 1989, 90, 1007.

(24) Kendall, R.; Dunning, T., Jr.; Harrison, R. J. Chem. Phys. 1992, 96,6769 .
(25) Varandas, A. J. C. J. Chem. Phys. 1989, 90, 4379.

(26) Hack, W.; Wagner, H. G.; Zaspypkin, A. Ber. Bunsen-Ges. 1994, 98,156

(27) Westley, F. Table of Recommended Rate Constants for Chemical Reactions Occuring in Combustion; NSRDS-NBS 67; NBS: Washington, DC, 1980.

(28) Whyte, A. R.; Phillips, L. F. Chem. Phys. Lett. 1983, 102, 451.

(29) Zhang, J.; Huang, R.; Zhuang, Q.; Zhang, C. Chem. Phys. Lett. $1990,174,568$

(30) Varandas, A. J. C. In Conical Intersections: Electronic Structure, Dynamics \& Spectroscopy; Domcke, W., Yarkony, D. R., Köppel, H., Eds.; Advanced Series in Physical Chemistry; World Scientific: River Edge, NJ, 2004; Chapter 5, p 91.

(31) Martínez-Núnez, E.; Varandas, A. J. C. J. Phys. Chem. A 2001, 105,5923

(32) Kaskan, W. E.; Hughes, D. E. Combust. Flame 1973, $20,381$.

(33) Skreiberg, O.; Kilpinen, P.; Glarborg, P. Combust. Flame 2004, 136, 501

(34) Catoire, L.; Luche, J.; Dupré, G.; Paillard, C. Shock Waves 2001 , $11,97$.

(35) Miller, J. A.; Branch, M. C.; McLean, W. J.; Chandler, D. W.; Smooke, M. D.; Klee, R. J. Proceedings of the Combustion Institute; The Combustion Institute: Pittsburgh, PA, 1985; Vol. 20, p 673.

(36) Peslherbe, G. H.; Wang, H.; Hase, W. L. Adv. Chem. Phys. 1999 105, 171 .

(37) Rodrigues, S. P. J.; Varandas, A. J. C. J. Phys. Chem. A 2003 , 107,5369

(38) Leroy, R. J. A Computer Program for Solving the Radial Schrödinger Equation for Bound and Quasi-Bound Levels, version 7.5; Chemica Physics Research Report CP-655; University Of Waterloo: Waterloo, Ontario, Canada, 2002.

(39) Varandas, A. J. C.; Silva, J. D. J. Chem. Soc., Faraday Trans. 1992, 88,941

(40) Hase, W. L.; Duchovic, R. J.; Hu, X.; Komornicki, A.; Lim, K. F.; Lu, D.; Peslherbe, G. H.; Swamy, K. N.; Linde, S. R. V.; Varandas, A. J. C.; Wang, H.; Wolf, R. J. QCPE Bull. 1996, 16, 43

(41) Varandas, A. J. C. In Conferencias Plenarias de la XXIII Reunión Bienal de Química; Feliciano, A. S., Grande, M., Casado, J., Eds.; Universidad de Salamanca: Salamanca, Spain 1991; p 321.

(42) Varandas, A. J. C. Faraday Discuss. Chem. Soc. 1987, 84, 353

(43) Walch, S. P. J. Chem. Phys. 1991, 95, 4277.

(44) Mota, V. C.; Varandas, A. J. C. To be published.

(45) Zhao, M.; Truhlar, D. G.; Blais, N. C.; Schwenke, D. W.; Kouri, D. J. J. Phys. Chem. 1990, 94, 6696

(46) Smith, G. P.; Golden, D. M.; Frenklach, M.; Moriarty, N. W Eiteneer, B.; Goldenberg, M.; Bowman, C. T.; Hanson, R. K.; Song, S.; Gardiner, W. C., Jr.; Lissianski, V. V.; Qin, Z. http://www.me.berkeley.edu/ gri mech (accessed Oct 2006).

(47) Jolicard, G.; Austin, E. J. Chem. Phys. 1986, 103, 295.

(48) Jolicard, G.; Leforestier, C.; Austin, E. J. J. Chem. Phys. 1988, 95 1026.

(49) Tennyson, J.; Henderson, J. R.; Fulton, N. G. Comput. Phys. Commun. 1995, 86, 175 .

(50) Li, G.; Guo, H. Chem. Phys. Lett. 2001, 347, 443. 